\title{
Study of the Physico-chemical Properties and Antioxidant Activity of Extracted Melanins
}

\author{
Pei-Hsing Hsieh ${ }^{1} \&$ Tu-Fa Lien ${ }^{1}$ \\ ${ }^{1}$ National Chiayi University, Department of Animal Science, Chiayi, Taiwan \\ Correspondence: Tu-Fa Lien, National Chiayi University, Department of Animal Science, Chiayi, Taiwan. \\ E-mail: tflien@mail.ncyu.edu.tw
}

Received: June 6, 2012 Accepted: June 25, 2012 Online Published: August 8, 2012

doi:10.5539/jas.v4n9p217 URL: http://dx.doi.org/10.5539/jas.v4n9p217

\begin{abstract}
Ultraviolet (UV) light tends to cause skin damage; melanin can scavenge reactive oxygen species (ROS) produced from UV to protect skin from damage caused by free radicals. The purpose of this study was to investigate the physico-chemical properties and antioxidant activity of extracted melanins. Melanins were extracted from black tea (BT-melanin), black soybean (BS-melanin) and black-bone silky fowl (SF-melanin); they were then compared with synthetic melanin (SY-melanin). Three kinds of extracted melanins have absorbance ability in broad-spectrum $(190-450 \mathrm{~nm})$ wavelength. The experiment's results indicated that the solubility in $25^{\circ} \mathrm{C}$ water, organic solvents, $1 \mathrm{M} \mathrm{NH}_{4} \mathrm{OH}$, and $1 \mathrm{M} \mathrm{HCl}$ of the three extracted melanins was similar to the solubility of synthetic melanin. The melanins also showed good stability in various light sources. The extracted melanins could chelate with $\mathrm{Fe}^{2+}$ and $\mathrm{Cu}^{2+}$. An in vitro study showed that the extracted melanin enhanced the survivability of fibroblast cells with $25 \mu \mathrm{g} \mathrm{mL}^{-1}$ concentration after UV irradiation $(254 \mathrm{~nm}, 0.09$ $\left.\mathrm{mW} \mathrm{cm}{ }^{2-1}\right)(\mathrm{p}<0.05)$. All of the extracted melanins increased glutathione peroxidase (GSH-Px) and catalase activity when exposed to UV light $(\mathrm{p}<0.001)$. They inhibited the peroxidation of lipid (TBARS) and scavenged superoxide anion $(\mathrm{p}<0.001)$ induced by UV irradiation. According to the above results, the melanins extracted from black tea, black soybean, and black-bone silky fowl are similar in their physico-chemical properties, and they have the capacity for anti-oxidation and photoprotection from UV irradiation.
\end{abstract}

Keywords: Physico-chemical properties, antioxidant activities, photoprotection, melanins

\section{Introduction}

Exposure to too much sunlight may cause erythema or ageing. Ultraviolet (UV) light especially tends to significantly affect skin and cause cell damage; even worse, it may result in skin cancer, for example, squamous cell carcinoma, basal cell carcinoma and melanoma (Reichrath, 2007). UV light also promotes gene mutation and DNA damage (Ravanat et al., 2001), produces reactive oxygen species (ROS) and increases oxidative damage (Herrling et al., 2006; Liu et al., 2009).

Some research indicates that melanin has a wide absorption spectrum because of its special structure and can protect skin from UV damage (Brenner \& Hearing, 2008). Melanin contains some function groups, such as $\mathrm{COOH}, \mathrm{OH}, \mathrm{SH}$ and $\mathrm{NH}_{2}$ groups; thus, melanin could supply and receive electrons and scavenge ROS produced from organisms or UV to protect from free radicals and lipid peroxidation (Bilgihan et al., 1995; Bochenek \& Gudowska-Nowak, 2003; Geng et al., 2008a).

Melanins are a ubiquitous class of biological pigments; they play an important role in photoprotection and antioxidation. Recent advances in the chemistry of melanins have demonstrated their diversity. The various types of melanin show different physico-chemical properties; their photobiological properties may not be unique (Ortonne, 2002).

Black tea has a known antioxidant property resulting from its polyphenols and catechins components. In addition, it contains melanin. The black-bone silky fowl is a special kind of chicken. This chicken has a high level of melanin in its skin, bone membrane and organs. There is also a high level of melanin on the peel of black soybeans

Few reports were concerned about the physico-chemical properties and the capacity of antioxidation of these three kinds of melanin. In this study, we investigated the feasibility of extracting melanin from black tea, black 
soybean and the skin of black-bone silky fowl. We also studied the physico-chemical properties of the extracted melanin and the capacity of the extracted melanin for photoprotection and antioxidation of fibroblast cells compared with the same capacity of synthetic melanin.

\section{Materials and Methods}

\subsection{Melanin Extraction}

Fully fermented black tea, black soybeans and silky fowl were bought at the market. The skin and the foot of the silky fowl were taken to extract the melanin.

\subsubsection{Crude Melanin Extraction}

Black tea was boiled with water at a ratio of $1: 10(\mathrm{w} / \mathrm{v})$ for $10 \mathrm{~min}$, followed by filtration. The black soybeans were washed with water and soaked overnight to separate the skin. $10 \% \mathrm{NH}_{4} \mathrm{OH}$ was added to the black tea and black soybean skin, and the $\mathrm{pH}$ was adjusted to 10.5 for $12 \mathrm{~h}$ to extract the melanin. After extraction, the mixture was filtered and centrifuged at 5,000 g for $20 \mathrm{~min}$ to obtain the melanin crude extract. The extracted crude melanin was acidified with $2 \mathrm{M} \mathrm{HCl}$ to $\mathrm{pH} 2.5$ at room temperature for $3 \mathrm{~h}$ and centrifuged at 5,000 $\mathrm{g}$ for 20 min.

The skin of the silky fowl was separated and washed. $10 \% \mathrm{NH}_{4} \mathrm{OH}$ was added to the chicken skin and blended. The mixture was boiled for $1 \mathrm{~h}$ and filtered. This crude extract was acidified with $2 \mathrm{M} \mathrm{HCl}$ to $\mathrm{pH} 2.5$ and centrifuged at 5,000 g for $20 \mathrm{~min}$.

Acid hydrolysis was applied to remove carbohydrates and proteins. The melanin was boiled in $7 \mathrm{M} \mathrm{HCl}$ for $2 \mathrm{~h}$, followed by centrifugation at $10,000 \mathrm{~g}$ for $10 \mathrm{~min}$ and rinsing with water. Solvents (chloroform, ethyl acetate and ethanol) were used to remove the lipids. In practice, $100 \mathrm{mg}$ of melanin were mixed with $50 \mathrm{~mL}$ of solvent, and left for $30 \mathrm{~min}$. The melanin was collected after filtration.

\subsubsection{Purify Crude Melanin}

The collected product was dissolved in $0.2 \% \mathrm{NH}_{4} \mathrm{OH}$, and the solution was subjected to repeated precipitations. This was followed a previously reported procedure (Sava et al., 2001) and centrifugation at 6,000 g for $10 \mathrm{~min}$. Melanin products were collected and analyzed.

The melanin solution was prepared using the following procedure. The filtered residue was dissolved in sterile distilled water in a slightly alkaline condition with $0.5 \mathrm{~mol} \mathrm{~L}^{-1} \mathrm{NH}_{3} \cdot \mathrm{H}_{2} \mathrm{O}$ to $\mathrm{pH} 9$, incubated at $50^{\circ} \mathrm{C}$ for $1 \mathrm{~h}$ and filtered. The ammonia was removed by a rotary evaporator under reduced pressure to a final $\mathrm{pH}$ of 7.5.

\subsection{Physico-chemical Properties of the Melanin Determination}

To determine the ultraviolet-visible absorption spectrum of the melanin, the absorption spectrum of the melanin solution was measured on a spectrophotometer (Hitachi U-1900, Japan). All of the absorption values were also determined with a spectrophotometer in the following experiments.

Firstly, to determine the dissolve capacity of different melanins in different solvents, $0.1 \mathrm{~g}$ of the melanin was added to $10 \mathrm{~mL}$ of water, aqueous acid, alkali (including $\mathrm{Na}_{2} \mathrm{CO}_{3}, \mathrm{NaOH}$ solution) and common organic solvents (including benzene, chloroform, ethanol, methanol, acetone, etc), and stirred at $25^{\circ} \mathrm{C}$ for $1 \mathrm{~h}$. The solution was filtered and the $\lambda_{\max }$ value was determined to ascertain the dissolving capacity of the melanin.

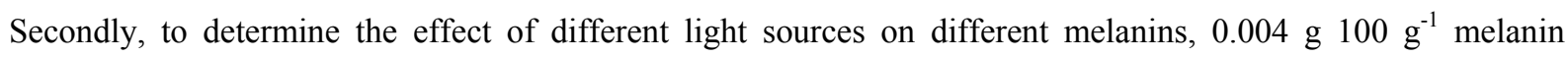
solutions were put under natural light, in a dark place or under ultraviolet light (10 volt) at a distance of $30 \mathrm{~cm}$ for a specific time (10 $\mathrm{min}$ ) and the $\lambda_{\max }$ value was determined.

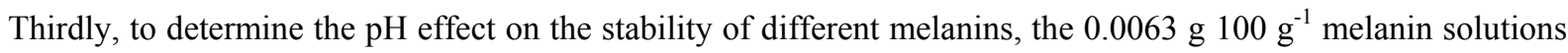
were adjusted to a $\mathrm{pH}$ of $3,5,7,9$ and 11 by $\mathrm{NaOH}$ or $\mathrm{HCl}$. The samples were kept at $25^{\circ} \mathrm{C}$ for $30 \mathrm{~min}$, and scanned with an absorption spectrum of 190-220 nm (determined to be a good absorption spectrum of melanin). The influence of $\mathrm{pH}$ on melanin was observed.

Finally, to determine different melanin chelating ability with different ions, the $15 \mathrm{mg} \mathrm{L}^{-1}$ solutions of $\mathrm{CuSO}_{4}$,

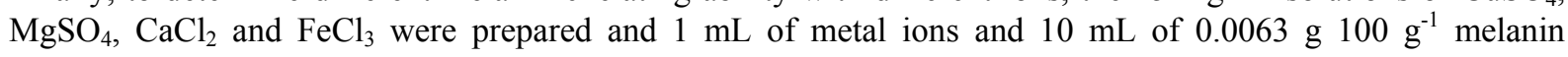
solutions were mixed. The $\lambda_{\max }$ value of homogenate was recorded.

\subsection{In Vitro Cell Culture Experiment}

\subsubsection{Cell Cultures}

Human fetal skin fibroblasts (CCRC NO. 60300) were cultured in minimum essential medium (Sigma) (pH 7.2-7.4) supplemented with $10 \%$ bovine serum, penicillin-streptomycin solution 100 unit $\mathrm{mL}^{-1}$ and amphotericin B solution $250 \mu \mathrm{g} \mathrm{mL}^{-1}$. 
The cell culture was divided into the following groups: 1) negative control (no added melanin), 2) positive control (no exposed UV light), 3) SY-melanin (synthesis melanin); 4) BT-melanin (black tea melanin); 5) BS-melanin (black soybean melanin); 6) SF-melanin (silk fowl melanin). The final melanin concentration was $25 \mu \mathrm{g} \mathrm{mL}{ }^{-1}$. Every group contained 15 flasks, and every flask $1 \mathrm{~mL}$ of $5 \times 10^{5}$ cells $\mathrm{mL}^{-1}$ cell suspension was added for culturing. The experiment groups were exposed to UV light for $30 \mathrm{~min}^{\mathrm{day}}{ }^{-1}$ for 5 days, except for the positive control. The successive 5-day UV dose was $810 \mathrm{~mJ} \mathrm{~cm}^{2-1}$.

\subsubsection{Cell Survival Ability Determined}

At the end of the cell culture, cell suspension samples were stained with $0.4 \%$ trypan blue to count the surviving cells with a hemocytometer.

\subsubsection{Cell Homogenate Preparation}

The cell suspensions ( 3 flasks were pooled) were centrifugated at 1,000 g for $5 \mathrm{~min}$ and the supernatant was removed. The cells were combined with $0.05 \mathrm{M}$ Tris- $\mathrm{HCl}$, put into liquid nitrogen for $15 \mathrm{~min}$ and then sonicated for $10 \mathrm{~min}$ by ultrasonic sieving. The above process was repeated 3 times and centrifugated at 2,500 $\mathrm{g}$ for $10 \mathrm{~min}$ The supernatant was obtained and stored at $-80^{\circ} \mathrm{C}$ for antioxidant activity analysis.

\subsubsection{Cell Protein Concentration Determined}

The protein concentration was determined by the Lowry method (Lowry et al., 1959).

\subsubsection{Antioxidant Activities Assay}

Catalase activity was determined according to the method suggested by Ellerby and Bredesen (2000), with catalase (C-1345, Sigma Co, USA) used as the standard. Glutathione peroxidase (GSH-Px) activity was conducted following the method reported by Bhat et al. (1992).

Scavenging superoxide activity was determined following the method described by Shi and Dalal (1991). The reaction began after $0.025 \mathrm{U} \mathrm{mL}^{-1}$ xanthine oxidase was added to a cuvette that contained $0.90 \mathrm{~mL}$ of reaction buffer (including $50 \mathrm{mM}$ potassium phosphate, $\mathrm{pH}$ 7.8; $1 \mathrm{mM}$ EDTA; $100 \mu \mathrm{M}$ nitroblue tetrazolium (NDT); 0.25 $\mathrm{g} \mathrm{kg}^{-1}$ triton $\mathrm{x}-100 ; 100 \mu \mathrm{M}$ hypoxanthine) and $50 \mu \mathrm{L}$ sample. The measurement was taken using a spectrophotometer at $560 \mathrm{~nm}$ for $5 \mathrm{~min}$.

Thiobarbituric acid-reactive substance (TBARS) was determined according to the procedure reported by Fraga et al. (1988). The peroxidative damage to lipids resulted in the production of malondialdehyde (MDA), which reacted with thiobarbituric acid under conditions of high temperature $\left(80^{\circ} \mathrm{C}, 90 \mathrm{~min}\right)$ and acidity (trichloroacetic acid) generation of chromogen that can be measured spectrophotometrically at $535 \mathrm{~nm}$. The unit was expressed as $\mathrm{nM} M D A \mathrm{~mL}^{-1}$.

\subsection{Statistical Analysis}

The experiment data were subjected to statistical analysis by GLM using the SAS (statistical analysis system) for variance analysis while the significant differences among the groups were determined using Tukey's test (SAS, 1998) according to the following model,

$$
\mathrm{Y}=\mu+\mathrm{T}_{\mathrm{i}}+\mathrm{e}_{\mathrm{ij}}
$$

Where $\mathrm{Y}$ denotes the dependent variable, $\mu$ represents for the mean, $\mathrm{T}$ is the treatment effect and e denotes the random residual error term. All values were presented as means and SD; the level of significant difference was set at $P<0.05$.

\section{Results and Discussion}

\subsection{Physico-chemical Properties}

\subsubsection{Appearance of Extracted Melanin}

There is a slight color difference among the extracted melanins from different sources. There are two kinds of melanin: eumelanin and pheomelanin. The color of eumelanin is between deep brown and black; pheomelanin's color is between red and tawny. The different ratio of these two kinds of melanin causes the different colors. Among them, SY-melanin is the most black and SF-melanin is a color similar to SY-melanin. BT-melanin and BS-melanin are a deep brown color (Figure 1). The degree of black color can be listed as SY-melanin $>$ SF-melanin $>$ BS-melanin $>$ BT-melanin. All of the melanins show granule particles. 

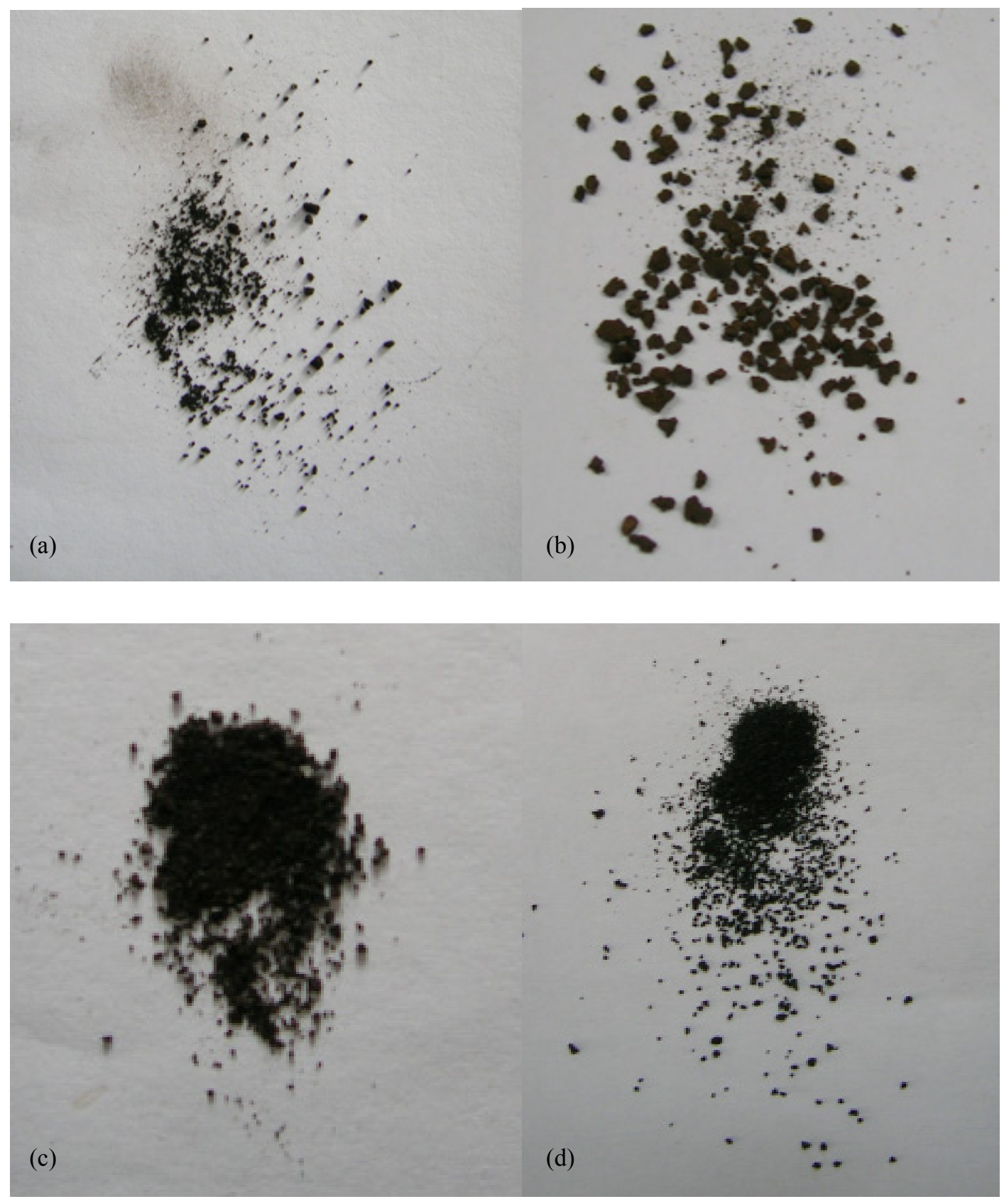

Figure 1. The appearance of melanin extracted from various sources (a) SY-melanin; (b) BT-melanin; (c) BS- melanin; (d) SF-melanin

\subsubsection{The Extracted Ratio}

The extracted ratio (melanin weight/stuffs weight) and relative concentration of melanin (melanin concentration/crude extracted melanin weight) are shown in Table 1. Table 1 reveals that the extracted ratio of BT-melanin is about $2 \%$ and the relative concentration is about $45 \%$. The extracted ratio and relative concentration of BS-melanin are $0.16 \%$ and $26 \%$; SF-melanin is $0.095 \%$ and $17 \%$. BT-melanin has the highest extracted ratio and relative concentration; SF-melanin is the lowest. 
Table 1. The extracted ratio and relative concentration of melanin extracted from various sources

\begin{tabular}{ccc}
\hline Sources & Extracted ratio (\%) & Relative concentration (\%) \\
\hline Black tea & $2.005 \pm 0.010$ & $45.33 \pm 0.58$ \\
Black soybean & $0.166 \pm 0.003$ & $26.67 \pm 1.53$ \\
Black-bone silky fowl & $0.095 \pm 0.002$ & $17.33 \pm 1.52$ \\
\hline
\end{tabular}

Values are mean $\pm \overline{\mathrm{SD}}(\mathrm{n}=3)$.

The extracted ratio $=($ the extracted melanin weight $/$ stuffs weight $) \times 100 \%$.

The relative concentration $=($ melanin concentration $/$ crude extracted melanin weight $) \times 100 \%$.

\subsubsection{UV Spectrum of Melanin Solution}

Melanin can be absorbed in wide spectrum visible light $(800-340 \mathrm{~nm})$ or UV light (340-200 nm), especially in the wavelength of UV. In the experiment, $20 \mu \mathrm{g} \mathrm{mL}^{-1}$ of melanin solution was prepared and the spectrum was scanned using a spectrophotometer. Figure 2 shows the results. The spectrum of BT-melanin is similar to that of SY-melanin, and there is a classical shoulder wavelength at $275 \mathrm{~nm}$ (Sava et al., 2001). The spectrum of BS-melanin is similar to that of SF- melanin. This result shows that these three kinds of extracted melanin have similar absorption in UV light. The BT-melanin has the highest absorption solution. Novikov et al. (2001) indicated that melanin extracted from black tea exhibits photoprotection activity and showed that this melanin intensively absorbs radiation in UV and visible light.

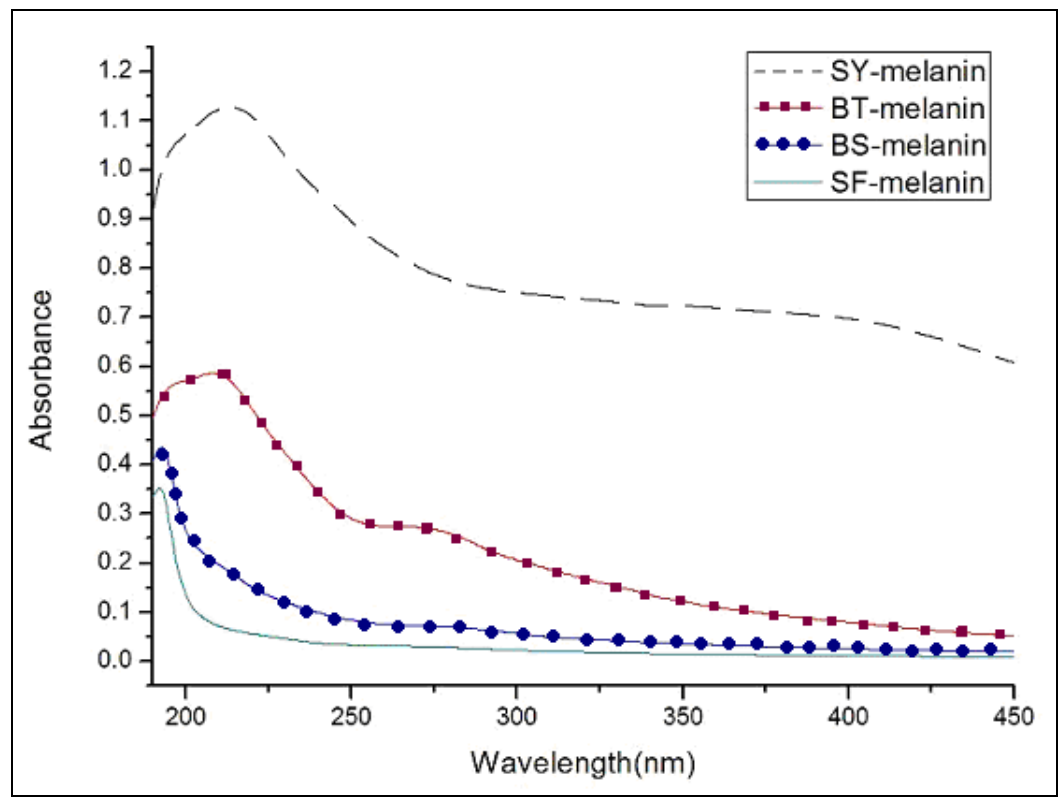

Figure 2. The UV spectrum pattern of melanin extracted from various sources. SY-melanin: Synthetic-melanin; BT-melanin: Black tea-melanin; BS-melanin: Black soybean-melanin; SF-melanin: Black-bone silky fowl-melanin

\subsubsection{Physical Properties of Extracted Melanin}

Table 2 shows the result of comparing the dissolving capacity of extracted melanins with synthesized melanin. The three extracted melanins could not dissolve in $25^{\circ} \mathrm{C}$ of water and organic solvents (methanol, ethanol, chloroform and acetone). They could dissolve in alkaline solution, which is a light yellow to brown color. The dissolving capacity of these three kinds of extracted melanins is similar to that of synthesized melanin. Melanin will precipitate in acid solution of a $\mathrm{pH}$ value of 3 . This is also similar to synthesized melanin. 
Table 2. Dissolved capacity of melanin extracted from various sources in different solvents

\begin{tabular}{lcccc}
\hline \multicolumn{1}{c}{ Tests } & BT-melanin BS-melanin SF-melanin SY-melanin \\
\hline $\mathrm{H}_{2} \mathrm{O}$ at $25^{\circ} \mathrm{C}$ & $\mathrm{N}$ & $\mathrm{N}$ & $\mathrm{N}$ & $\mathrm{N}$ \\
Methanol & $\mathrm{N}$ & $\mathrm{N}$ & $\mathrm{N}$ & $\mathrm{N}$ \\
Ethanol & $\mathrm{N}$ & $\mathrm{N}$ & $\mathrm{N}$ & $\mathrm{N}$ \\
Chloroform & $\mathrm{N}$ & $\mathrm{N}$ & $\mathrm{N}$ & $\mathrm{N}$ \\
Acetone & $\mathrm{N}$ & $\mathrm{N}$ & $\mathrm{N}$ & $\mathrm{N}$ \\
$1 \mathrm{~N} \mathrm{NH}_{4} \mathrm{OH}(5 \mathrm{mg} / 10 \mathrm{ml})$ & $\mathrm{P}$ & $\mathrm{P}$ & $\mathrm{P}$ & $\mathrm{P}$ \\
Precipitation by $1 \mathrm{~N} \mathrm{HCl}$ & $\mathrm{P}$ & $\mathrm{P}$ & $\mathrm{P}$ & $\mathrm{P}$ \\
$(\mathrm{pH} \mathrm{2})$ & & & & \\
\hline
\end{tabular}

$\mathrm{N}$ : negative response; $\mathrm{P}$ : positive response.

\subsubsection{The Effect of Light Sources on the Stability of the Melanin}

UV in sunshine will injure organisms, but melanin is able to absorb UV light well. Organisms also produce melanin to protect themselves from UV damage. In this experiment, the three kinds of melanin solutions were placed in natural light, UV light and in dark conditions. Table 3 shows the results of the observations of the influence of different light sources on the melanin solutions. After 5 days of testing, the light absorbance of these three melanin solutions showed no difference to each other with respect to having been in natural light, UV light or in dark conditions. Thus, it is shown that these three kinds of melanin solutions will not be damaged by the visible spectrum and UV light. They have good stability when exposed to light.

Table 3. Effect of light sources on stability of the melanin

\begin{tabular}{lcllll}
\hline Groups & Light source & $0 \mathrm{~d}$ & $1 \mathrm{~d}$ & $3 \mathrm{~d}$ & $5 \mathrm{~d}$ \\
\hline \multirow{4}{*}{ BT-melanin } & UV light & $0.454 \pm 0.008$ & $0.457 \pm 0.013$ & $0.457 \pm 0.012$ & $0.465 \pm 0.014$ \\
& Nature light & $0.455 \pm 0.015$ & $0.461 \pm 0.018$ & $0.462 \pm 0.011$ & $0.459 \pm 0.015$ \\
& Dark & $0.449 \pm 0.026$ & $0.455 \pm 0.029$ & $0.452 \pm 0.031$ & $0.447 \pm 0.026$ \\
& UV light & $0.457 \pm 0.009$ & $0.473 \pm 0.013$ & $0.476 \pm 0.005$ & $0.466 \pm 0.011$ \\
BS-melanin & Nature light & $0.466 \pm 0.014$ & $0.475 \pm 0.004$ & $0.479 \pm 0.006$ & $0.473 \pm 0.020$ \\
& Dark & $0.468 \pm 0.013$ & $0.459 \pm 0.028$ & $0.466 \pm 0.016$ & $0.457 \pm 0.024$ \\
& UV light & $0.248 \pm 0.002$ & $0.250 \pm 0.007$ & $0.249 \pm 0.011$ & $0.251 \pm 0.010$ \\
SF-melanin & Nature light & $0.249 \pm 0.004$ & $0.251 \pm 0.005$ & $0.257 \pm 0.004$ & $0.255 \pm 0.003$ \\
& Dark & $0.247 \pm 0.003$ & $0.249 \pm 0.005$ & $0.250 \pm 0.004$ & $0.257 \pm 0.002$ \\
\hline
\end{tabular}

Values are mean $\pm \mathrm{SD}(\mathrm{n}=3)$.

UV light is 10 volt.

\subsubsection{The Effect of Different $\mathrm{pH}$}

Figure 3 shows the absorbance of melanin solutions under different $\mathrm{pH}$. Melanin can dissolve in alkaline solution and precipitate in $\mathrm{pH} 2-3$. The result shows that the absorbance of melanin in alkaline is higher than in acid. When the $\mathrm{pH}$ decreases, the absorbance also decreases. The results of melanin extracted from different sources are the same. Thus, the solubility of these three kinds of melanin is obviously influenced by the $\mathrm{pH}$ value.

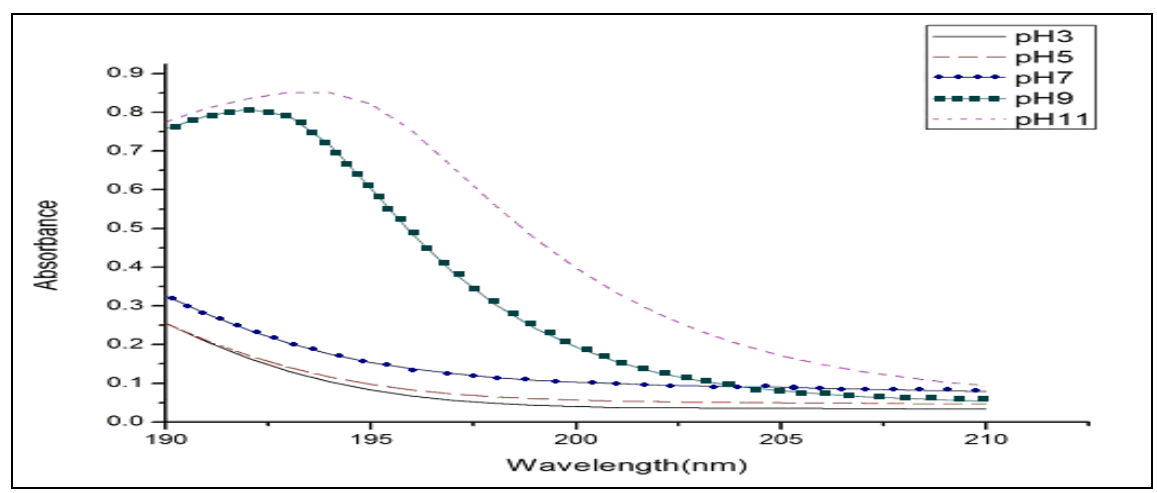

(a) 


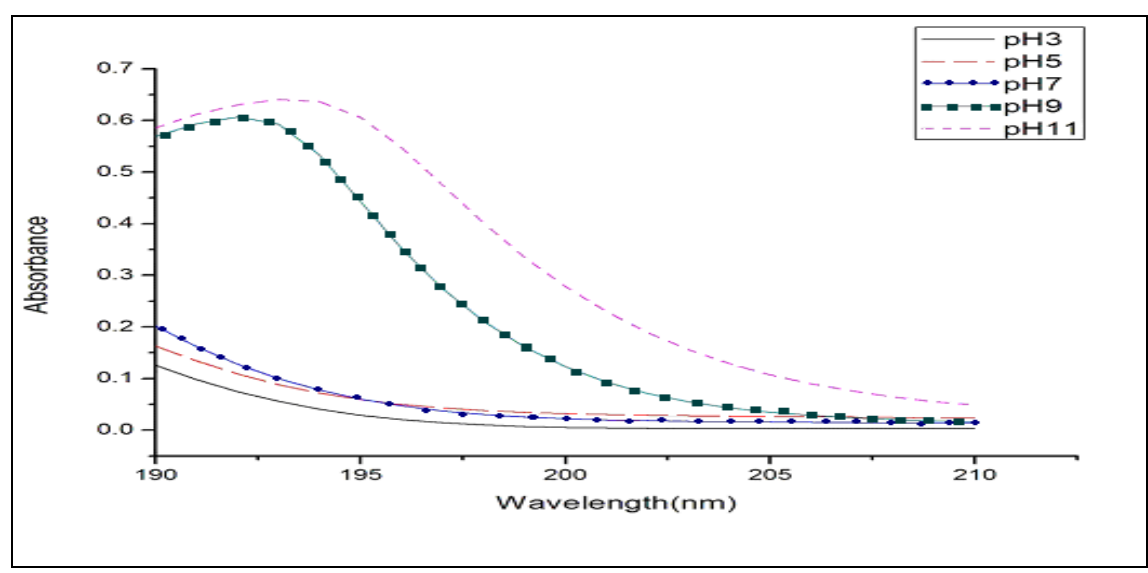

(b)

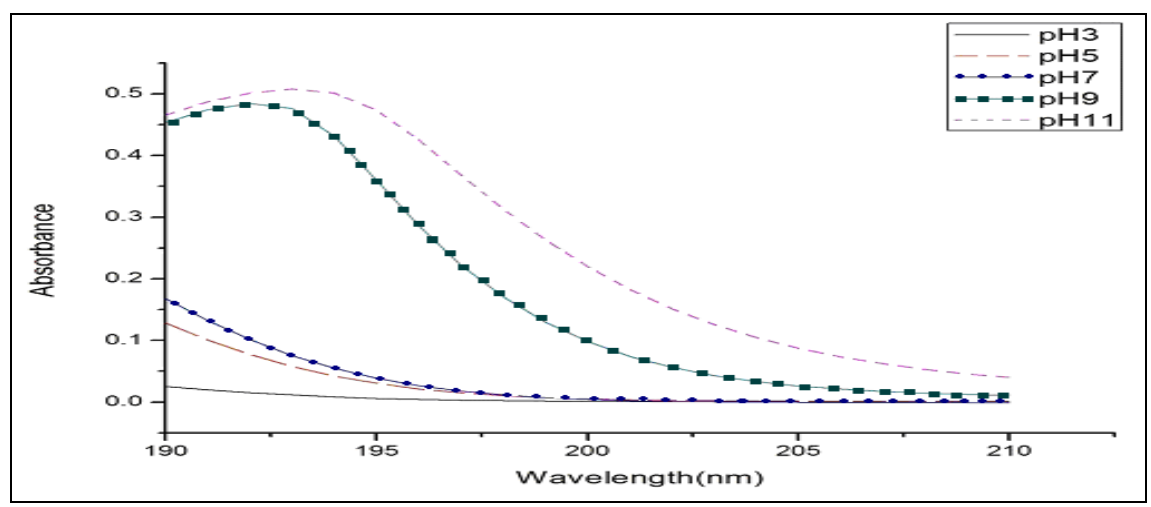

(c)

Figure 3. Effect of $\mathrm{pH}$ on absorption spectrum of melanin

(a) BT-melanin; (b) BS-melanin; (c) SF-melanin

\subsubsection{Effect of Metal Ions on the Stability of the Melanin}

Figure 4 shows the result of different kinds of metal ions influenced by different melanins. The figure indicates that the three kinds of melanin showed great chelation with $\mathrm{Fe}^{2+}$; BS-melanin and SF-melanin showed good chelation with $\mathrm{Cu}^{2+}$. These three kinds of melanin do not have apparent chelation with other ions. Wang et al. (2006) pointed out that $\mathrm{Mg}^{2+}$ will reduce the color of melanin, but we did not observe that phenomenon in this experiment. Szpoganicz et al. (2002) indicated that synthesized melanin chelated with $\mathrm{Cu}^{2+}$ and $\mathrm{Zn}^{2+}$ in different pH. Melanin can also be chelated with $\mathrm{Ca}^{2+}$ and prevent the DNA damage by $\mathrm{H}_{2} \mathrm{O}_{2}$ (Hoogduijn et al., 2004). Bush and Simon (2007) also indicated that melanin has been implicated in maintaining calcium homeostasis in the cell. Hong and Simon (2005) revealed that cow choroid melanosomes had a higher binding capacity for the carboxylate-binding metal ions (e.g., $\mathrm{Mg}^{2+}, \mathrm{Ca}^{2+}$ ). However, this phenomenon in these three melanins was not observed in this study.

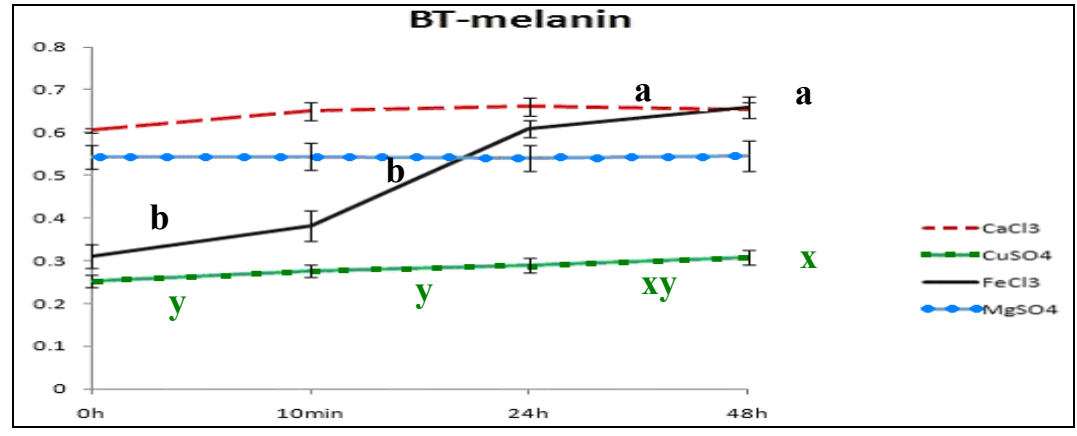

(a) 


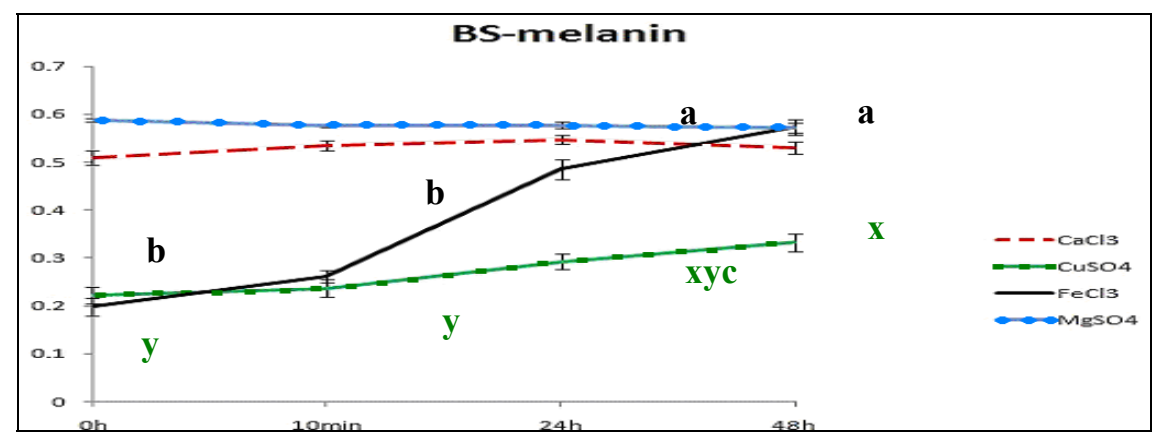

(b)

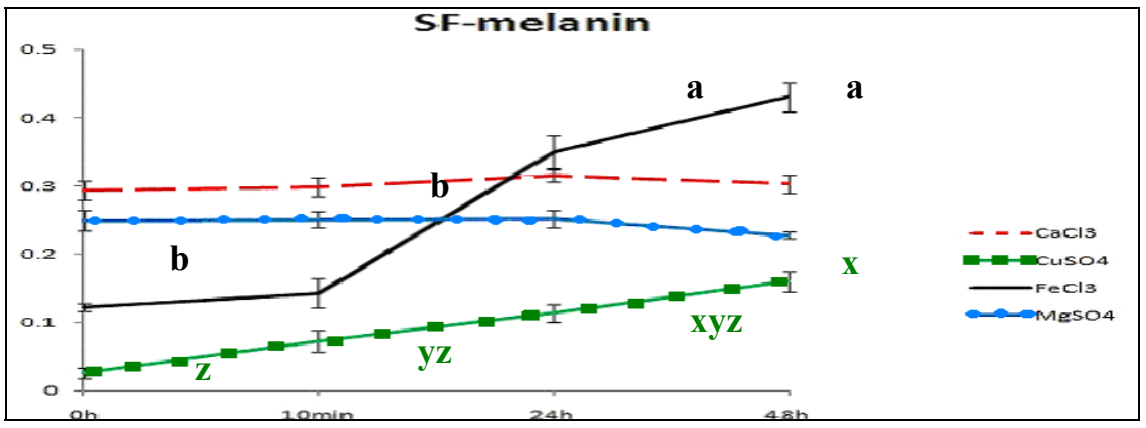

(c)

Figure 4. Effect of metal-ion on the stability of the melanin

Error bars represent standard deviations of means (n=3). (a) BT-melanin; (b) BS-melanin; (c) SF-melanin. Values are mean $\pm \mathrm{SD}(\mathrm{n}=3)$. ${ }^{\mathrm{a}-\mathrm{z}}$ Means within the same color with different superscripts differ significantly $(\mathrm{p}<0.05)$.

\subsection{The Antioxidation of Melanin}

Yen et al. (2000) indicated that UV light could induce DNA mutation. It will cause damage to the DNA structure as well as play a role in gene mutation, diseases and cancers. Furthermore, UV will induce ROS and free radicals; this will generate oxidized damage for the organism and induce lipid peroxidation (Herrling et al., 2006; Jee et al., 2009).

\subsubsection{The Survival of Cultured Cells}

The results are shown in Table 4: the survival rate of the negative control was obviously lower than that of the positive control. The survival rate of each test group was not obviously different from that of the positive control. This proved that UV will cause death to the fibroblast, and that SY-melanin, BT-melanin, BS-melanin and SF-melanin can protect the fibroblast from UV damage.

Table 4. The survival rate of cultured cells after UV irradiation

\begin{tabular}{lcc}
\hline Experimental conditions & Cell density $\left(\times 10^{6}\right.$ cell $\left./ \mathrm{ml}\right)$ & Survival $(\%)$ \\
\hline MEM + SY-melanin & $3.53 \pm 0.29^{\mathrm{a}}$ & 96.98 \\
MEM + BT- melanin & $3.56 \pm 0.25^{\mathrm{a}}$ & 97.80 \\
MEM + BS- melanin & $3.58 \pm 0.18^{\mathrm{a}}$ & 98.35 \\
MEM + SF- melanin & $3.19 \pm 0.12^{\mathrm{a}}$ & 87.64 \\
Positive control & $3.64 \pm 0.14^{\mathrm{a}}$ & 100 \\
Negative control & $2.36 \pm 0.30^{\mathrm{b}}$ & 64.84
\end{tabular}

Values are mean $\pm \mathrm{SD}(\mathrm{n}=5)$. ${ }^{\mathrm{a}, \mathrm{b}}$ Means within the column with different superscripts differ significantly $(\mathrm{p}<0.05)$. Survival $(\%)=($ treatment or negative control cells / positive control cells) $\times 100 \%$. Positive control: cells no exposed UV irradiation. Negative control: cells exposed UV irradiation. 
After UV radiation, the fibroblast will cause shape changing, damage and even death. This consistent with the results of Archambault et al. (1995) and Jee et al. (2009). They also reported that melanin could protect the skin from UV damage and scavenge ROS to avoid lipid peroxidation. Geng et al. (2008b) reported that the cell viability of fibroblast treated with varied doses of bacterial-derived melanin increased dramatically and became more resistant to UVA-induced apoptosis in comparison with the untreated control. Photoprotection against UV damage appears primarily to involve optical absorption/scattering by the melanin (Menter \& Willis, 1997).

3.2.2 Influence on the Glutathione Peroxidase (GSH-Px) Activity of Fibroblast with Melanin Solutions Exposed to UV Irradiation

In Figure 5, the GSH-Px activity of BT-melanin, BS-melanin and SF-melanin groups show apparent promotion. The results compared to the negative/positive control were conspicuous $(\mathrm{p}<0.001)$. BT-melanin, BS-melanin and SF-melanin could increase the GSH-Px activity. GSH-Px activity of the SY-melanin group was not different from that of the positive control, but the catalase activity was apparently raised; this indicated that GSH has greater affinity to $\mathrm{H}_{2} \mathrm{O}_{2}$, and that it preserves catalase activity.

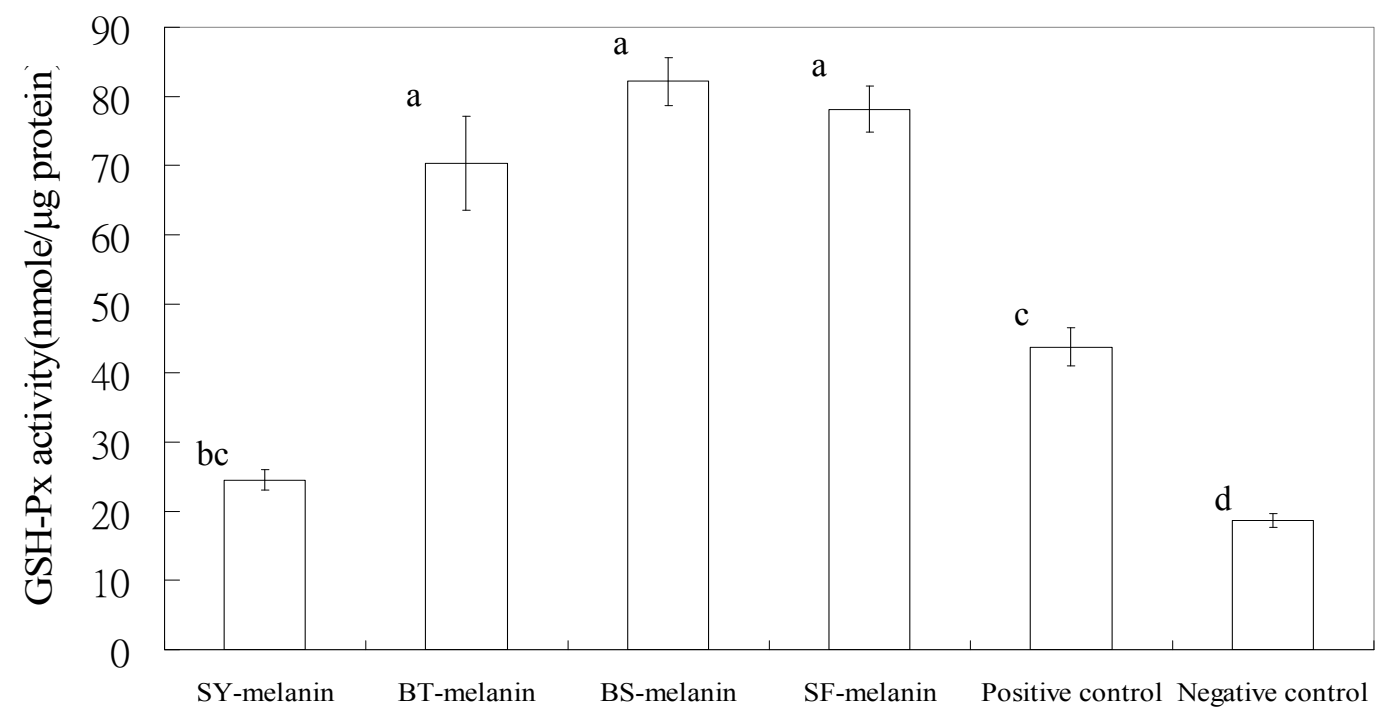

Figure 5. Influence on the glutathione peroxidase activity of fibroblast culture with melanin solutions exposed to UV irradiation. Each bar presented as the means $\pm \mathrm{SD}(\mathrm{n}=5)$.

a,b,c,d Means with different superscripts differ significantly $(\mathrm{p}<0.001)$.

Hung et al. (2003) showed that melanin extracted from black tea could protect the liver cells of a mouse, avoid damage from free radicals induced by hydrazine ( $\mathrm{Hz})$ and maintain the GSH level. Geng et al. (2008b) added the melanin extracted from bacteria showed that they could protect cells from $\mathrm{UV}$ and $\mathrm{H}_{2} \mathrm{O}_{2}$ damage.

3.2.3 Influence on the Catalase Activity of Fibroblast with Melanin Solutions Exposed to UV Irradiation

Figure 6 shows that the SY-melanin and BT-melanin groups could cause an obvious increase in the catalase activity. BS-melanin and SF-melanin show no difference compared to the positive control but are obviously higher than the negative control. The GSH-Px activity of these two groups was about doubled compared to the positive control. We conjectured that a high level of GSH was sufficient to remove $\mathrm{H}_{2} \mathrm{O}_{2}$ induced by UV. Therefore, the catalase level was not influenced. 


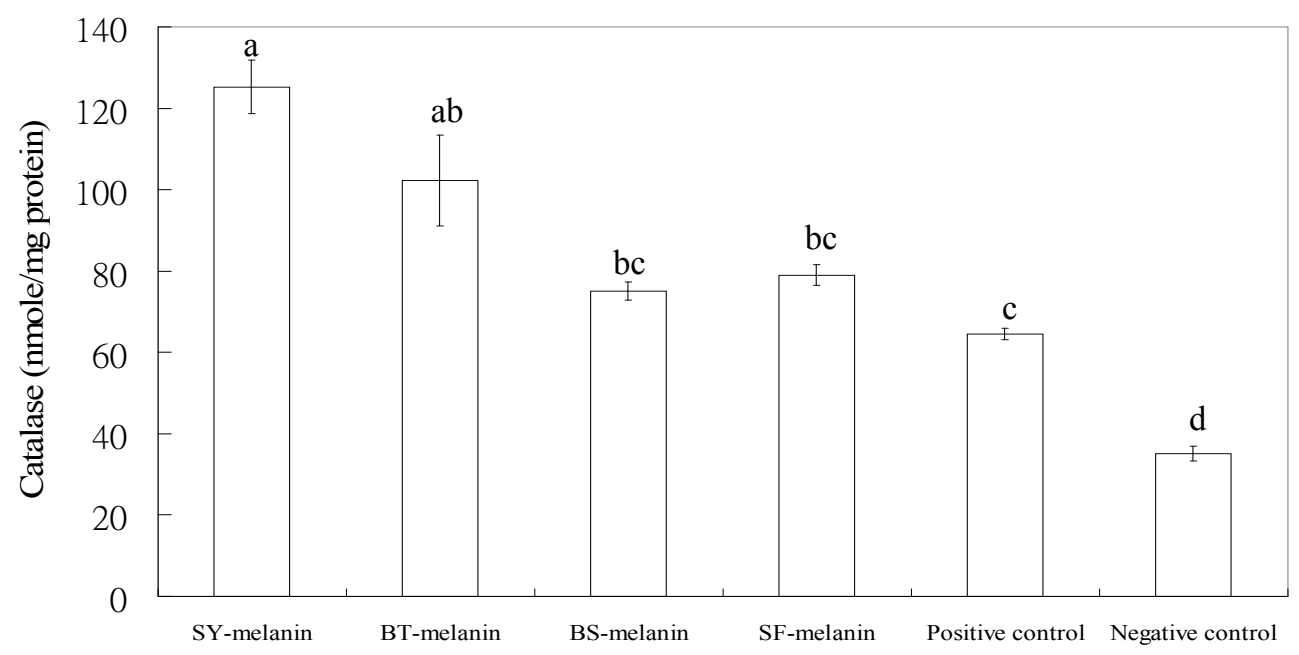

Figure 6. Influence on the catalase activity of fibroblast with melanin solutions exposed to UV irradiation.

Each bar presented as the means $\pm \mathrm{SD}(\mathrm{n}=5)$.

${ }^{\mathrm{a}, \mathrm{b}, \mathrm{c}, \mathrm{d}}$ Means with different superscripts differ significantly $(\mathrm{p}<0.001)$.

\subsubsection{Inhibition of Lipid Peroxidation (TBARS) of Fibroblast Culture with Melanin Solution Exposed to UV} Irradiation

Figure 7 demonstrates that all of the melanin groups show apparent inhibition of lipid peroxidation compared to the negative control $(\mathrm{p}<0.001)$. This indicated that melanin could inhibit the lipid peroxidation induced by UV irradiation and recover to a normal level. Bilgihan et al. (1995) reported that melanin extracted from the eye could effectively inhibit lipid peroxidation to prevent uveitis. Sava et al. (2003) indicated that melanin extracted from black tea could inhibit the MDA production and lipid peroxidation of liver cells when exposed to free radicals. Hung et al. (2007) added a different concentration of melanin extracted from black tea in mouse drinking water, which decreased the TBARS production of the kidney. Tu et al. (2009) also reported that the different doses of melanin extracted from silky fowl and synthesized melanin could both decrease lipid peroxidation of the egg. This experiment has the same result as in the above description and shows that melanin can inhibit lipid peroxidation.

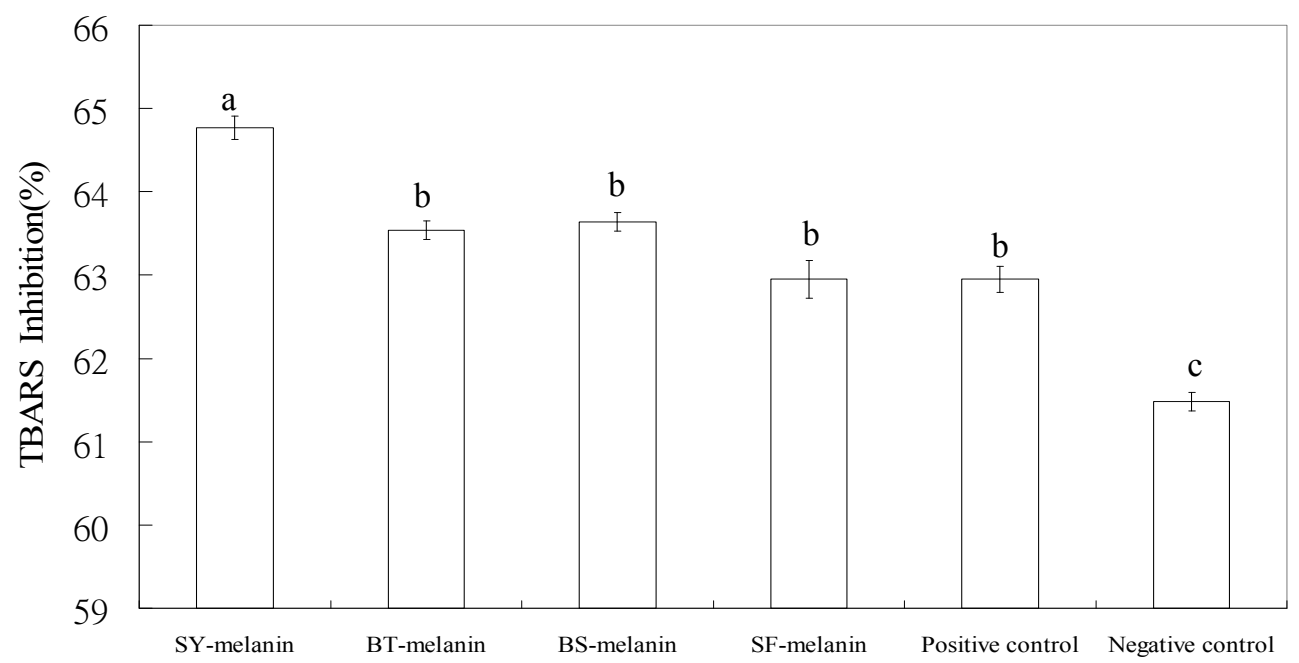

Figure 7. Inhibition of lipid peroxidation (TBARS) by fibroblast culture with melanin solution exposed to UV irradiation. Each bar presented as the means $\pm \operatorname{SD}(n=5)$.

${ }^{a, b, c}$ Means with different superscripts differ significantly $(p<0.001)$. 


\subsubsection{The Scavenging Capacity of Superoxide Anion Induced by UV Irradiation}

The results are displayed in Figure 8, indicating that melanin has the scavenging capacity of superoxide anion. All the test groups could scavenge superoxide anion $(\mathrm{p}<0.001)$. At the same concentration $\left(25 \mu \mathrm{g} \mathrm{mL}^{-1}\right)$, the scavenging capacity of SY-melanin was $80 \%$, and BT-melanin, BS-melanin and SF-melanin were $60 \%$.

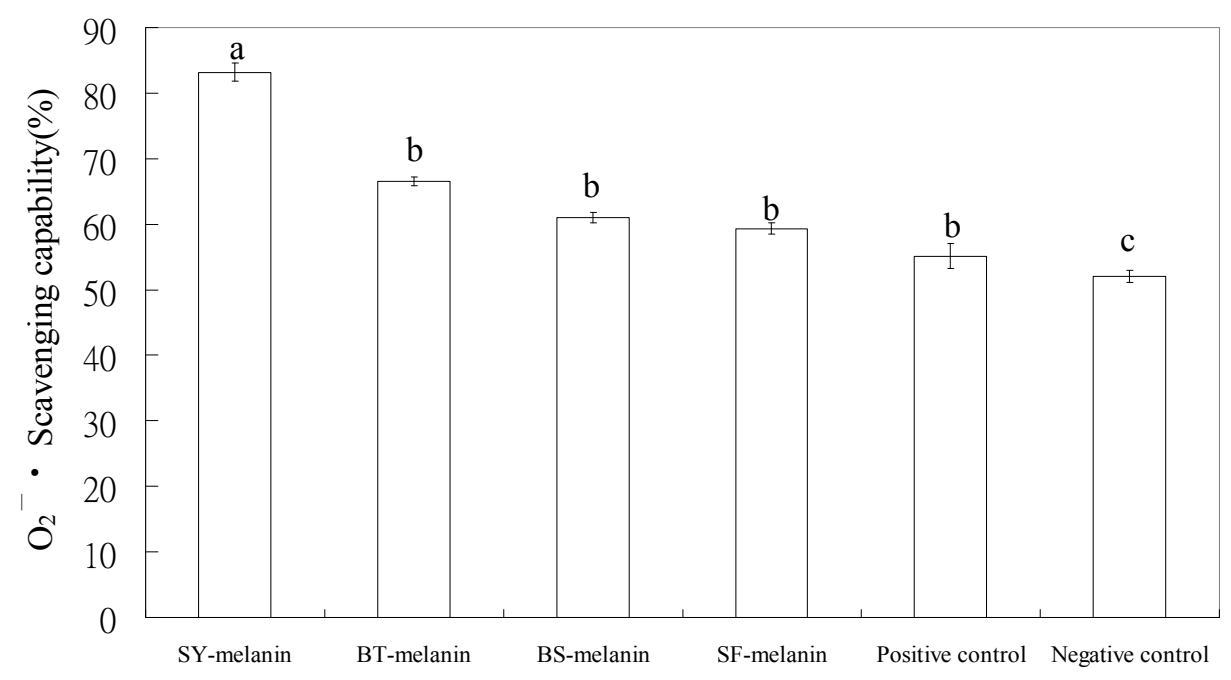

Figure 8 . The scavenging capacity of superoxide anion induced by UV irradiation.

Each bar presented as the means $\pm \operatorname{SD}(n=5)$.

${ }^{a, b, c}$ Means with different superscripts differ significantly $(\mathrm{p}<0.001)$.

Blarzino et al. (1998) indicated that DHICA-melanin, DHI-melanin and Dopa-melanin had the scavenging capacity of superoxide anion and the scavenging capacity was higher than $90 \%$ with $100 \mu \mathrm{g} \mathrm{mL}^{-1}$. Tu et al. (2009) reported that melanin extracted from the muscle of silky fowl had the same ability of scavenging superoxide anion and the same effectiveness dependent on the concentration. Wang et al. (2008) reported that a significant decrease in singlet oxygen production was observed in the presence of eumelanin extracted from pig retinal pigment epithelium cells. Melanin interacted with free radicals via the simple one-electron transfer processes (Rózanowska et al., 1999). Many reports had shown that melanin had a great ability to scavenge superoxide anion, and our experiment also had the same result as the abovementioned literatures.

\section{Conclusion}

The experiment results show that the melanins extracted from black tea, black soybean and black-bone silky fowl are similar in their physico-chemical properties, and have the capacity for antioxidation and photoprotection from UV irradiation.

\section{References}

Archambault, M., Yaar, M., \& Gilchrest, B, A. (1995). Keratinocytes and fibroblasts in a human skin equivalent model enhance melanocyte survival and melanin synthesis after ultraviolet irradiation. J. Invest. Dermatol., 104, 859-867. http://dx.doi.org/10.1111\%2F1523-1747.ep12607034

Bhat, G. B., Tinsley, S. B., Tolson, J. K., \& Patel, J, M. (1992). Hypoxia increases the susceptibility of pulmonary artery endothelial cells to hydrogen peroxide injury. J. Cell Phys., 151, 228-238. http://dx.doi.org/10.1002\%2Fjcp.1041510203

Bilgihan, A., Bilgihan, M. K., Akata, R. F., Aricioglu, A., \& Hasanreisolu, B. (1995). Antioxidative role of ocular melanin pigment in the model of lens induced uveitis. Free Rad. Biol. Med., 19, 883-885. http://dx.doi.org/10.1016\%2F0891-5849\%2895\%2900093-D

Blarzino, C., Mosca, L., Foppoli, C., Coccia, R. De., Marco, C., \& Rosei, M. A. (1998). Lipoxygenase $/ \mathrm{H}_{2} \mathrm{O}_{2}$-catalyzed oxidation of dihydroxyindoles: synthesis of melanin pigments and study of their antioxidant properties. Free Rad. Biol. Med., 26, 446-453. http://dx.doi.org/10.1016\%2FS0891-5849\%2898\%2900225-1 
Bochenek, K., \& Gudowska-Nowak, E. (2003). Fundamental building blocks of eumelanins: electronic properties of indolequinone-dimers. Chem. Phys. Lett., 373, 532-538. http://dx.doi.org/10.1016\%2FS0009-2614\%2803\%2900629-8

Brenner, M., \& Hearing, V. J. (2008). The Protective Role of Melanin Against UV Damage in Human Skin. Photochem. Photobiol., 84, 539-549. http://dx.doi.org/10.1111\%2Fj.1751-1097.2007.00226.x

Bush, W. D., \& Simon, J. D. (2007). Quantification of $\mathrm{Ca}(2+)$ binding to melanin supports the hypothesis that melanosomes serve a functional role in regulating calcium homeostasis. Pigment. cell Res. 20, 134-139.

Ellerby, L. M., \& Bredesen, D. E. (2000). Measurement of cellular oxidation, reactive oxygen species, and antioxidant enzymes during apotosis. Method In Ezymol., 322, 413-421. http://dx.doi.org/10.1016\%2FS0076-6879\%2800\%2922040-5

Fraga, C. G., Leibovitz, B. E., \& Tappel, A. L. (1988). Lipid peroxidation measured as thiobarbituric acid-reactive substance in tissue slices: Characrization and comparison between homogenates and microsome. Free Rad. Biol. Med., 4, 155-161.

Geng, J., Yu, S., Wan, X., Wang, X., Shen, P., Zhou, P., \& Chen, X. (2008a). Protective action of bacterial melanin against DNA damage in full UV spectrums by a sensitive plasmid-based noncellular system. $J$. Biochem. Biophys. Methods, 70, 1151-1155. http://dx.doi.org/10.1016\%2Fj.jprot.2007.12.013

Geng, J., Tang, W., Wan, X., Zhou, Q., Wang, X. J., Shen, P., Lei, T. C., \& Chen, X. D. (2008b). Photoprotection of bacterial-derived melanin against ultraviolet A-induced cell death and its potential application as an active sunscreen. J. Eur. Acad. Dermat. Venereol., 22, 852-858. http://dx.doi.org/10.1111\%2Fj.1468-3083.2007.02574.x

Herrling, T., Jung, K., \& Fuchs, J. (006). Measurements of UV-generated free radicals/reactive oxygen species (ROS) in skin. Spectrochim. Acta Part A, 63, 840-845. http://dx.doi.org/10.1016\%2Fj.saa.2005.10.013

Hong, L., \& Simon, J. D. (2005). Physical and chemical characterization of iris and choroid melanosomes isolated from newborn and mature cows. Photochem. Photobiol., 81, 517-523. http://dx.doi.org/10.1111\%2Fj.1751-1097.2005.tb00219.x

Hoogduijn, M. J., Cemeli, E., Ross, K., Anderson, D., Thody, A. J., \& Wood, J. M. (2004). Melanin protects melanocytes and keratinocytes against $\mathrm{H}_{2} \mathrm{O}_{2}$-induced DNA strand breaks through its ability to bind $\mathrm{Ca}^{2+}$. Exp. Cell Res., 294, 60-67. http://dx.doi.org/10.1016\%2Fj.yexcr.2003.11.007

Hung, Y. C., Sava, V. M., Blagodarsky, V. A., Hong, M. Y., \& Huang, G. S. (2003). Protection of tea melanin on hydrazine-induced liver injury. Life Sci., 72, 1061-1071. http://dx.doi.org/10.1016\%2FS0024-3205\%2802\%2902348-2

Hung, Y. C., Huang, G. S., Lin, L. W., Hong, M. Y., \& Se, P. S. (2007). Thea sinensis melanin prevents cisplatin-induced nephrotoxicity in mice. Food Chem. Toxicol., 45, 1123-1130. http://dx.doi.org/10.1016\%2Fj.fct.2006.12.017

Jee, H. J., Kim, H., Kim, A. J., Bae, Y., Bae, S., \& Yun, J. (2009). UV light induces premature senescence in Akt1-null mouse embryonic fibroblasts by increasing intracellular levels of ROS. Biochem. Biophys. Res. Commun., 383, 358-362. http://dx.doi.org/10.1016\%2Fj.bbrc.2009.04.017

Liu, S., Mizu, H., \& Yamauchi, H. (2010). Photoinflammatory responses to UV-irradiated ketoprofen mediated by the induction of ROS generation, enhancement of cyclooxygenase-2 expression, and regulation of multiple signaling pathways. Free Rad. Biol. Med., 48, $772-780$. http://dx.doi.org/10.1016\%2Fj.freeradbiomed.2009.12.014

Lowry, O. H., Rosebrough, N. J., Farr, A. L., \& Kandall, R. J. (1951). Protein measurement with the folin phenol reagent. J. Biol. Chem., 193, 381-385.

Memoli, S., Napolitano, A., d'Ischia, M., Misuraca, G., Palumbo, A., \& Prota, G. (1997). Diffusible melanin-related metabolites are potent inhibitors of lipid peroxidation. Biochim. Biophys. Acta, 1346, 61-68. http://dx.doi.org/10.1016\%2FS0005-2760\%2897\%2900018-0

Menter, J. M., \& Willis, I. (1997). Electron transfer and photoprotective properties of melanins in solution. Pigment. Cell Res., 10, 214-217. http://dx.doi.org/10.1111\%2Fj.1600-0749.1997.tb00487.x

Novellino, L., Napolitano, A., \& Prota, G. (2000). Isolation and characterization of mammalian eumelanins from hair and irides. Biochim. Biophys. Acta Gen. Subj., 1475, 295-306. http://dx.doi.org/10.1016\%2FS0304-4165\%2800\%2900080-5 
Novikov, D. A., Kurchenko, V. P., \& Azarko, II. (2001). Photoprotective properties of melanins from grape (Vitis vinifera) and black tea (Thea sinensis). Radiats. Biol. Radioecl., 41, 664-670.

Ortonne, J. P. (2002). Photoprotective properties of skin melanin. Br. J. Dermatol., 61, 7-10. http://dx.doi.org/10.1046\%2Fj.1365-2133.146.s61.3.x

Ravanat, J. L., Douki, T., \& Cadet, J. (2001). Direct and indirect effects of UV radiation on DNA and its $\begin{array}{llllll}\text { components. } J . & \text { Photochem. } & \text { Photobiol. } & \text { B, } & \text { 63 }\end{array}$ http://dx.doi.org/10.1016\%2FS1011-1344\%2801\%2900206-8

Reichrath, J. (2007). Sunlight skin cancer and vitamin D: What are the conclusions of recent findings that protection against solar ultraviolet (UV) radiation causes 25-hydroxyvitamin D deficiency in solid organ-transplant recipients, xeroderma pigmentosum, and other risk groups? J. Steroid Biochemi. Mol. Biol., 103, 664-667. http://dx.doi.org/10.1016\%2Fj.jsbmb.2006.12.029

Rózanowska, M., Sarna, T., Land, E. J., \& Truscott, T. G. (1999). Free radical scavenging properties of melanin interaction of eu- and pheo-melanin models with reducing and oxidising radicals. Free Rad. Biol. Med., 26, 518-525.

SAS Institute Inc. (1998). SAS user guide: statistic. SAS Inst., Cary, NC 1998.

Sava, V., Yang, S. M., Hong, M. Y., Yang, P. C., \& Huang, G. S. (2001). Isolation and characterization of melanic pigments derived from tea and tea polyphenols. Food Chem., 73, 177-184. http://dx.doi.org/10.1016\%2FS0308-8146\%2800\%2900258-2

Shi, X., \& Dalal, N. S. (1991). Antioxidant behavior of caffeine: Effect scavenging of hydroxyl radicals. Food Chem. Toxic., 29, 1- 6.

Szpoganicz, B., Gidanian, S., Kong, P., \& Farmer, P. (2002). Metal binding by melanins: studies of colloidal dihydroxyindole-melanin, and its complexation by $\mathrm{Cu}(\mathrm{II})$ and $\mathrm{Zn}(\mathrm{II})$ ions. J. Inorg. Biochem., 89, 45-53. http://dx.doi.org/10.1016\%2FS0162-0134\%2801\%2900406-8

Tu, Y., Sun, Y., Tian, Y., Xie, M., \& Chen, J. (2009). Physicochemical characterisation and antioxidant activity of melanin from the muscles of Taihe Black-bone silky fowl (Gallus gallus domesticus Brisson). Food Chem., 114, 1345-1350. http://dx.doi.org/10.1016\%2Fj.foodchem.2008.11.015

Wang, H., Pan, Y., Tang, X., \& Huang, Z. (2006). Isolation and characterization of melanin from Osmanthus fragrans' seeds. LWT - Food Sci. Technol., 39, 496-502. http://dx.doi.org/10.1016\%2Fj.lwt.2005.04.001

Wang, A., Marino, A. R., Gasyna, Z., Gasyna, E., \& Norris, J. Jr. (2008). Photoprotection by porcine eumelanin against singlet oxygen production. Phottochem. Photobiol., 84, 679-682. http://dx.doi.org/10.1111\%2Fj.1751-1097.2008.00353.x

Yen, G. C., Hung, Y. L., \& HSsieh, C. L. (2000). Protective effect of extracts of Mesona procumbens Hemsl. On DNA damage in human lymphocytes exposed to hydrogen peroxide and UV irradiation. Food Chem. Toxicol., 38, 747-754. http://dx.doi.org/10.1016\%2FS0278-6915\%2800\%2900069-7 